\title{
DURABILITY AND CHROMATIC BEHAVIOUR IN CEMENT PASTES CONTAINING CERAMIC INDUSTRY MILLING AND GLAZING BY-PRODUCTS
}

\author{
María Isabel Sánchez de Rojas ${ }^{1 *}$, Moisés Frías ${ }^{1}$, Elvira Sabador ${ }^{1}$, Eloy Asensio ${ }^{1}$, Julián \\ Rivera $^{1}$, Cesar Medina ${ }^{2}$ \\ 1. Department Cements and Materials Recycling, Eduardo Torroja Institute for Construction \\ Science, Spanish Council for Scientific Research (CSIC), 28033 - Madrid, Spain \\ 2. Department of Construction, School of Engineering, University of Extremadura, \\ UEX-CSIC Partnering Unit (SOSMAT), 10071 - Cáceres, Spain
}

\begin{abstract}
The decay in mortar and concrete induced by extremely aggressive agents is normally the result of the agent-binder reaction. Cement composition and characteristics therefore determine the durability of the mortars and concretes of which they form part. The existing legislation envisages the use of different types of additions in cement, which have a direct effect on the durability of elements in buildings and civil works. This study addressed the inclusion of ceramic industry milling and glazing sludge as an active addition in cement. The reuse of this industrial waste is consistent with environmental policies that seek to reduce or eliminate spoil heaps by recycling industrial waste and by-products as raw materials, in keeping with circular economy principles. The research conducted makes an innovative contribution to the valorisation of this waste, and highlights the resistance of blended cement pastes to chemical agents, further to the Koch \& Steinegger method. Water-induced decay in freeze/thaw situations was also studied. The processes involved were identified by analysing the mineralogical variations detected with X-ray diffraction, the morphological alterations
\end{abstract}


observed with scanning electron microscopy and the mercury porosimetric findings on pore size distribution.

The suitability of these binders for aesthetically demanding applications was also explored by measuring the colour in anhydrous cements and pastes exposed to aggressive chemical agents. For the first time, a correlation was established between colour parameters and the formation of the reaction products generated during chemical attack.

Keywords: Durability, colour alteration, cement, supplementary cementitious materials, ceramic waste.

Corresponding author: Tel +34913020440, Fax +34913020700

E-mail address: $\underline{\text { srojas@ietcc.csic.es }}$

\section{Introduction}

Generally speaking, mortar and concrete decay induced by extremely aggressive agents is the result of the agent-cement paste reaction. Therefore, all other parameters (aggregate type, water/cement ratio and type of admixtures) being equal, decay can be attributed to the cement. The physical and especially the chemical characteristics of cement, as well as the replacement ratio, affect decay, which is instrumental in mechanical strength. Hardening rate and final strength also impact durability. Likewise decisive in reactions with aggressive agents are the chemical composition, crystallinity or otherwise and porosity of cement hydration products, as cement susceptibility depends on those factors. The presence of calcium silicate or aluminate hydrates and especially portlandite is a determinant in cement durability. 
The existing legislation ${ }^{1}$ envisages the inclusion in cements of several types of supplementary cementitious materials, which play a prominent role in durability. The higher resistance to aggressive agents in cement bearing pozzolanic additions has been chiefly attributed to microstructural pore refinement, low pore solution alkalinity and low portlandite content. ${ }^{2-5}$ The Koch-Steinegger method was used in this study to explore the chemical resistance of hydrated cement paste blended with ceramic sludge. ${ }^{6}$ Water-induced decay in freeze/thaw conditions was also analysed, for the increased volume of water freezing in capillary pores is known to induce decay ${ }^{7}$ and microcracking. That in turn lowers mechanical strength and raises the penetrability of the concrete matrix by aggressive substances, with a concomitantly detrimental effect on durability. The processes involved in cement decay were defined by analysing the mineralogical variations detected with X-ray diffraction and the morphological changes observed with scanning electron microscopy. The reasons for the variations in pore size distribution, found with mercury porosimetry, were also explored.

The findings further showed that ceramic sludge nor contributed to chromatic change in cement paste exposed to aggressive agents, a highly promising feature from the standpoint of the inclusion of this waste in binders used to manufacture architectural (cast-in-place or precast) concrete.

Valorisation of the ceramic sludge generated during milling and glazing has been analysed in connection with new cement design. 8,9

A company in Spain that collects sludge generated by fired clay plants optimises ceramic sludge for use in the construction industry. In earlier research the present authors verified the pozzolanicity of ceramic sludge and the benefits of its inclusion in cement. ${ }^{10}$ 
Reuse in construction is one of the avenues for recycling waste as envisaged in current waste management policies informed by new, circular economy premises in which 'waste' is upgraded to 'raw material' status. One of the highest added value applications of waste in construction, its use as pozzolans or active additions in cement, serves as the inspiration for this study.

\section{Materials and methods}

\subsection{Materials}

The following materials were used in this study.

-Ceramic sludge (CS) from waste generated by the fired clay industry during clay milling, glaze preparation and product glazing, sourced from a ceramic sludge management company working out of Spain's Valencian region.

-Ordinary portland (OPC), EN 197- $1^{1}$ CEM I/42.5 N cement (i.e., clinker content greater than or equal to $95 \%$ and up to $5 \%$ of additional components).

-Blended cements (CS-PC) prepared with $20 \mathrm{wt} \%$ ceramic sludge (CS) and $80 \mathrm{wt} \%$ OPC.

\subsection{Techniques}

-Fineness was determined on a Sympatec (Bergstadt-Clausthal-Zellerfeld, Germany) Helos 12 KA laser diffractometer using isopropyl alcohol as a dispersant.

-Chemical composition, found with a Bruker (Karlsruhe, Germany) S8 Tiger X-ray fluorescence (XRF) spectrometer fitted with a $4 \mathrm{~kW}$ rhodium anticathode tube, was explored in molten beads. A mix containing $1 \mathrm{~g}$ of sample, $10 \mathrm{~g}$ of flux (34\% lithium metaborate and $66 \%$ lithium tetraborate) and two drops of a lithium bromide non-wetting agent was fused in 
a propane gas bead maker at approximately $1000^{\circ} \mathrm{C}$.

-Chloride and $\mathrm{SO}_{3}$ content as well as loss on ignition (LoI) were determined as recommended in European standard EN 196-2 ${ }^{11}$ (chemical analysis of cement).

The reactive silica content was found further to European standard EN 197-1. ${ }^{1}$ Free lime and soluble phosphates were quantified as recommended in European standard EN 450-1. ${ }^{12}$

-The minority elements were analysed on a Varian (Melbourne, Australia) 725-ES inductively coupled plasma - optical emission spectrometer (ICP-OES).

- Mineralogical composition was analysed on a BRUKER GmbH (Karlsruhe, Germany) AXS D8 X-ray powder diffractor fitted with a $3 \mathrm{~kW}$ copper $(\mathrm{Cu} \mathrm{K \alpha 1.2)}$ anode, wolfram cathode X-ray generator. Scans were taken at $2 \theta$ angles of $5^{\circ}$ to $60^{\circ}$ at $2^{\circ} /$ minute. The standard operating conditions for the voltage generator tube were $40 \mathrm{kV}$ and $30 \mathrm{~mA}$.

-Paste morphology was studied under a JEOL (Akishima, Japan) JSM 5400 scanning electron microscope (SEM) fitted with a Bruker (Berlin, Germany) energy dispersive X-ray (EDX) analyser.

- The porosity tests were conducted on a Micromeritics (Norcross, GA, United States) 9500 mercury pore sizer.

- Colour measurements were read with a Minolta (Tokyo, Japan) handheld CM-2500d spectrophotometer fitted with a data processor. The measurements were based on the $\mathrm{L}^{*} \mathrm{a} * \mathrm{~b}^{*}$ colour space, in which $\mathrm{L}^{*}$ is lightness and $\mathrm{a}^{*}$ and $\mathrm{b}^{*}$ the colour coordinates. Lightness is ranked on a scale of 0 to 100 , in which 0 is absolute black and 100 perfect white. The coordinates $\mathrm{a}^{*}$ and $\mathrm{b}^{*}$ range respectively from red to green and yellow to blue. ${ }^{13}$ Colour was measured in the hydrated pastes exposed to aggressive agents. 


\subsection{Test methods}

- The Koch-Steinegger ${ }^{6}$ method was applied to study durability in cement pastes with a water/cement ratio of 0.5 containing $0 \%$ to $20 \%$ ceramic sludge $(\mathrm{CS})$. The pastes were poured into $1 \times 1 \times 6 \mathrm{~cm}^{3}$ steel moulds, demoulded after storage for $24 \mathrm{~h}$ at $100 \%$ relative humidity and cured by soaking in deionised water at $20 \pm 1{ }^{\circ} \mathrm{C}$ for $21 \mathrm{~d}$. The samples were then submerged in deionised water (the reference medium) or $\mathrm{NaCl}, \mathrm{Na}_{2} \mathrm{SO}_{4}$ or simulated seawater ${ }^{14}$ at $20{ }^{\circ} \mathrm{C}$ for $14 \mathrm{~d}, 56 \mathrm{~d}$ or $90 \mathrm{~d}$. All the specimens were weighed before exposure to the aggressive media and at the specified ages. Before weighing they were rinsed with deionised water to remove any surface deposits and gently dried with a moist cloth.

Resistance to these media was determined by comparing the flexural strength values of the specimens soaked in the experimental to those of the samples soaked in deionised water.

The Koch-Steinegger ${ }^{6}$ criterion for resistance is a $56 \mathrm{~d}$ corrosion index (ratio of the flexural strength of samples soaked in aggressive $\left(\mathrm{F}_{\mathrm{sx}}\right)$ to the strength of water-soaked $\left(\mathrm{F}_{\mathrm{sw}}\right)$ samples $)$ of over 0.7 .

- The freeze/thaw test was conducted on the same $1 \times 1 \times 6 \mathrm{~cm}^{3}$ specimens as described above, likewise stored in moulds at $100 \%$ relative humidity for $1 \mathrm{~d}$ and subsequently soaked in deionised water at $20 \pm 1{ }^{\circ} \mathrm{C}$ for $28 \mathrm{~d}$. They were then exposed to 49 full freeze-thaw cycles, each consisting in freezing at $-20^{\circ} \mathrm{C}$ under moist conditions followed by thawing to $20^{\circ} \mathrm{C}$. Damage was assessed on the grounds of mechanical tests and microstructural analysis. 


\section{Results and Discussion}

\subsection{CS characterisation}

The laser diffraction study showed that the CS particles ranged in size from $100 \mu \mathrm{m}$ to $1 \mu \mathrm{m}$, with $50 \%$ of the particles $<12 \mu \mathrm{m}$ and $90 \%<43 \mu \mathrm{m}$.

Further to the data given in Table 1, the sludge had high silica, aluminium oxide and iron oxide contents, together amounting to over $70 \mathrm{wt} \%$. As reactive silica accounted for $33.10 \mathrm{wt} \%$, the waste met the EN $197-1^{1}$ requirement for pozzolanicity. ${ }^{10}$

It was shown to have no free lime, a sulfate content (expressed as $\mathrm{SO}_{3}$ ) of $0.10 \%$. and a chloride content of $<0.10 \%$.

Minority elements (Table 2) including lead, barium, zinc, titanium, zirconium and chromium accounted for a significant $9.91 \%$ of the total. These elements are included in the sludge at different stages of ceramic material manufacture. ${ }^{7}$ Previous studies ${ }^{10}$ showed that while the amounts involved are legislation-compliant, ${ }^{1}$ these elements retard setting time slightly, a finding consistent with reports by other authors, ${ }^{15-18}$ who observed that certain zinc, titanium and zirconium oxides delay cement hydration.

TABLE 1. Majority constituents in starting materials (wt\%)

TABLE 2. Minority constituents in starting materials (wt\%)

According to the X-ray diffraction findings, in previous studies, ${ }^{10}$ the main crystalline phases in the CS were: quartz, kaolinite, muscovite, illite, hematite, magnetite, calcit, dolomite, albite and zircon (zirconium silicate). 


\subsection{Durability of CS-bearing cement paste}

\subsubsection{Resistance to aggressive agents}

\subsubsection{Variations in specimen mass after exposure to aggressive media}

The percentage variations in concrete paste mass induced by the aggressive media (Figure 1) were calculated as per Equation [1]:

$$
\text { [1] } \Delta W(\%)=\frac{m x-m 0}{m 0} \times 100
$$

where: $m_{x}$ is the mass after exposure to aggressive media and $m_{0}$ the initial value.

Mass gain is normally due to salt precipitation inside pores and on the surface of their walls. $^{19-20}$

The scantly significant $(< \pm 0.5 \%)$ variations in weight in water-soaked specimens have been associated by some authors with water imbibition during hydration. ${ }^{21}$ Weight alterations in $\mathrm{NaCl}$ were similarly insignificant, ranging from $+0.70 \%$ to $-0.15 \%$. In contrast, gains of up to $5 \%$ were recorded for the specimens soaked in $\mathrm{Na}_{2} \mathrm{SO}_{4}$, an indication that this is one of the most destructive salts. Its effects are associated with the pressure exerted by the crystallisation of mirabilite $\left(\mathrm{Na}_{2} \mathrm{SO}_{4} 10 \mathrm{H}_{2} \mathrm{O}\right)$, a decahydrate. ${ }^{20}$ The greatest rise in weight, $>8 \%$, observed in the $90 \mathrm{~d}$ OPC specimens exposed to seawater, was attributed to salt formation. ${ }^{22}$

\subsubsection{Mechanical tests}

Further to the flexural strength findings shown in Figure 2, the OPC specimens exposed to 
$\mathrm{Na}_{2} \mathrm{SO}_{4}$ and seawater were the ones most acutely affected by aggressive agents. Flexural strength also declined in the CS-PC pastes, although less steeply. The sharpest downturn in compressive strength (Figure 3) was observed in the OPC exposed to $\mathrm{Na}_{2} \mathrm{SO}_{4}$.

Nonetheless, in the $14 \mathrm{~d}$ specimens, flexural and compressive strength values were higher in the OPC and CS-PC pastes exposed to $\mathrm{Na}_{2} \mathrm{SO}_{4}$ than in the water-soaked specimens. Such initial higher strength was attributed to the rise in density attendant upon the formation of salts that filled the pores. The values tended to descend drastically at longer exposure times, however, due to the adverse effects of expansive product formation, the mechanism which, as noted by other authors ${ }^{23}$, makes this a particularly aggressive agent. A similar pattern was observed in seawater, although the effect was much more accentuated in the OPC than in the CS-PC specimens.

In $\mathrm{NaCl}, 56 \mathrm{~d}$ specimen compressive strength rose and remained high through $90 \mathrm{~d}$ in CS-PC, but declined at that age in OPC. Some authors attributed the rise in strength in blended cements to the formation of more hydration product, ${ }^{24}$ favoured by enhanced $\mathrm{Ca}(\mathrm{OH})_{2}$ solubility and greater $\mathrm{C}-\mathrm{S}-\mathrm{H}^{25}$ stability in $\mathrm{NaCl}$, where part of the $\mathrm{Na}+$ can be taken up into the C-S-H interlayers. ${ }^{26}$

As the CS-PC specimens exhibited Koch-Steinegger corrosion indices of over 0.7 (Table 3), these pastes may be deemed to be resistant to all the aggressive media studied, whereas the OPC specimens, with values of $<0.7$, were neither seawater- nor NaCl-resistant. Durability was consistently higher in the CS-PC than in the OPC pastes.

TABLE 3. Corrosion indices (Fsx/Fsw) for OPC and CS-PC pastes versus time (days) 
The flexural/compressive $\left(\mathrm{F}_{\mathrm{sx}} / \mathrm{C}_{\mathrm{sx}}\right)$ strength ratios for the $14 \mathrm{~d}, 56 \mathrm{~d}$ and $90 \mathrm{~d}$ OPC and CS-PC specimens in aggressive media are shown in Table 4 . The $14 \mathrm{~d}$ ratios were very similar in the OPC and CS-PC pastes, irrespective of the medium. The $56 \mathrm{~d}$ and $90 \mathrm{~d} \mathrm{~F}_{\mathrm{sx}} / \mathrm{C}_{\mathrm{sx}}$ ratio was higher in the CS-PC than in the OPC pastes, however. The explanation for that difference with age lies in the presence of pozzolanic materials, which induce more rapid flexural than compressive strength development. The additioned pastes were therefore more flexible and elastic than the initial portland cement, due to the nature of the hydration products forming during the pozzolanic reaction. ${ }^{27-28}$

TABLE 4. $\mathrm{F}_{\mathrm{sx}} / \mathrm{C}_{\mathrm{sx}}$ ratios for $\mathrm{OPC}$ and CS-PC pastes after soaking in aggressive solutions versus time (days)

\subsubsection{X-ray diffraction findings}

The XRD patterns for water-cured OPC and CS-PC pastes are reproduced in Figure 4 and the crystalline compounds detected are listed with their COD ID in Table 5. The main crystalline phases identified were calcium monocarboaluminate, portlandite, calcite and anhydrous dicalcium silicate in the form of larnite, which remained intact after water curing due to its slower hydration. $^{29}$

Monocarbonate, portlandite, calcite and anhydrous larnite were also observed in the CS-PC specimens, along with the zircon and quartz present in the CS as discussed earlier. The intensity of the portlandite reflections declined as a result not only of lower cement content, but also of the pozzolanic reaction induced by the $\mathrm{CS} .{ }^{10}$ 
The sulfate and chloride ions present in seawater (Figure 5, Table 5) interacted in the pastes cured in that medium. $\mathrm{Cl}^{-}$ions, which are highly mobile, diffuse across the pore system, favouring the formation of Friedel's salt $^{30}$ (calcium monochloroaluminate hydrate: $3 \mathrm{CaOAl}_{2} \mathrm{O}_{3} \mathrm{CaCl}_{2} \mathrm{Al}_{2} \mathrm{O}_{3} \cdot 10 \mathrm{H}_{2} \mathrm{O}$ ) and subsequently ettringite when the salt reacts with $\mathrm{SO}_{4}{ }^{2-}$ ions. Calcium monocarboaluminate all but disappeared in these specimens. No Kruzel's salt $\left(3 \mathrm{CaOAl}_{2} \mathrm{O}_{3} \frac{1}{2} \mathrm{CaCl}_{2} \frac{1}{2} \mathrm{CaSO}_{4} \cdot 11 \mathrm{H}_{2} \mathrm{O}\right)$ was observed, although other authors have contended that it may be present. ${ }^{24}$ Brucite $\left(2 \theta: 18.42^{\circ}, 37.73^{\circ}\right)$, the result of the reaction between the $\mathrm{Mg}^{2+}$ in seawater and the $\mathrm{OH}^{-}$ions in portlandite, was also clearly visible. The diffraction lines for portlandite were significantly less intense than in the water-soaked specimens, an indication of the direct effect of seawater attack on that hydration product. Although ettringite $\left(2 \theta: 9.09^{\circ}, 23.42^{\circ}\right)$ was also observed, its scantly significant presence may have been due to the brucite-induced blockage of ion transport. The resulting decline in $\mathrm{SO}_{4}{ }^{2-}$ concentration would have constrained secondary ettringite formation. ${ }^{31}$ The intensity of the brucite reflections in the CS-PC paste was lower than found for the OPC specimens.

Friedel's salt was identified in the specimens soaked in $\mathrm{NaCl}$ (Figure 6, Table 5) because chloride ion diffusion, which favoured the $\mathrm{Cl}^{-}-\mathrm{C}_{3} \mathrm{~A}$ reaction, curbed its conversion to ettringite. ${ }^{30}$ Portlandite presence remained unaltered in both the OPC and CS-PC pastes.

Gypsum formed in all the paste specimens exposed to $\mathrm{Na}_{2} \mathrm{SO}_{4}$ (Figure 7, Table 5), although the respective diffraction line was more intense in the OPC than in the CS-PC pastes. Pozzolanic additions such as $\mathrm{CS}$ can react with $\mathrm{CH}$ to yield $\mathrm{C}-\mathrm{S}-\mathrm{H}$, lowering the portlandite content and with it gypsum formation in the presence of alkaline sulfates. ${ }^{32}$ 
TABLE 5. Mineralogical data for OPC and CS-PC

\subsubsection{Scanning electron microscopy (SEM) - energy dispersive X-ray (EDX) findings}

SEM (fracture mode) analysis of the $56 \mathrm{~d}$ water-soaked OPC and CS-PC pastes revealed the presence of portlandite in the form of compact plates (Figures 8(a) and 8(b)) in both. The mean size of these plates was smaller and their distribution more disperse in the latter, however, due to the pozzolanic reaction attendant upon CS-PC hydration, as discussed in the section on the XRD findings.

$\mathrm{C}-\mathrm{S}-\mathrm{H}$ gel was also observed. The EDX analyses of the OPC pastes yielded $\mathrm{Ca} / \mathrm{Si}$ ratios, based on 10 readings, of 2.10, whereas the findings (also based on 10 readings) for the CS-PC pastes revealed aluminium uptake in the C-S-H gel. The Si replacement by Al in the gel led to lower $\mathrm{Ca} / \mathrm{Si}$ ratios (1.72). The foregoing was consistent with premises set out by other authors $^{33-35}$ as well as with earlier results ${ }^{10}$ for the $\mathrm{CS} / \mathrm{Ca}(\mathrm{OH})_{2}$ system and cements containing granite sludge ${ }^{36}$ in which the addition of pozzolans led to lower $\mathrm{Ca} / \mathrm{Si}$ ratios than found in OPC.

A surface layer with a predominance of magnesium in the form of brucite was detected in the $56 \mathrm{~d}$ seawater-soaked OPC specimens (Figure 9(a)), corroborating the XRD findings. That coating was the result of a superficial seawater attack, inasmuch as the mineral was not identified in specimen interiors. Although thinner, a brucite layer was likewise observed in the CS-PC pastes (Figure 9(b)). Gypsum was also identified in the OPC and CS-PC pastes, more visibly in the former.

Portlandite persisted in the $56 \mathrm{~d}, \mathrm{NaCl}$-soaked OPC and CS-PC specimens (Figure 10(a) and 
Figure 10(b)), although the more significant presence of phases containing $\mathrm{Al}, \mathrm{Cl}$ and $\mathrm{Ca}$ might denote the existence of Friedel's salt (plates).

In external sulfate attack, damage is associated with the formation of different amounts of salts such as gypsum, expansive secondary ettringite and, in some cases, thaumasite. Here, the OPC and CS-PC pastes exposed to sodium sulfate were found to contain gypsum, C-S-H gels and pores filled with ettringite needles and portlandite plates. No new compounds were observed in the CS-PC pastes, which nonetheless contained gypsum (albeit less than in OPC), ettringite needles and portlandite. As noted earlier, the pozzolanic reaction lowers the portlandite content and with it gypsum formation in the presence of alkaline sulfates. ${ }^{32}$

\author{
3.2.1.5 Effect of porosity on resistance to aggressive agents \\ Construction materials are normally non-uniform, porous solids. Their properties and \\ durability are closely related to their porosity and particularly to their pore size \\ distribution. $^{25,37-39}$
}

Figure 11 shows the pore size distributions of $56 \mathrm{~d}$ OPC and CS-PC pastes soaked in different media. As a rule, the CS-PC pastes tended to have smaller pore sizes than the OPC (pores smaller than 0.01 microns), the result of the pozzolanic reaction between the CS and the portlandite generated during cement hydration. The concomitant formation of further hydration products filled and refined the pores, determining higher chemical resistance to aggressive media and therefore durability in CS-PC than in OPC paste. The resulting higher 
Koch-Steinegger indices described above were consistent with those reported by Bassuoni ${ }^{40}$ for fly ash, as well as with the results observed for masonry waste. ${ }^{28}$

\subsubsection{Freeze-thaw cycles}

The OPC reference and the CS-PC (bearing $20 \%$ ceramic sludge) specimens after 49 freeze-thaw cycles are studied. Specimen brittleness determined decay and material loss in both materials. The CS-PC specimens collapsed altogether.

\subsubsection{X-ray diffraction findings}

The X-ray diffraction analyses of the OPC and CS-PC pastes after 49 freeze-thaw cycles showed a higher ettringite content than in the water-soaked specimens, particularly in the CS-PC paste. Ettringite was not deemed to have induced specimen destruction, however, which was attributed to physical rather than chemical effects, as discussed in connection with the mercury porosimetry findings.

\subsubsection{Effect of porosity on freeze-thaw resistance}

The mercury porosimetry analyses revealed a shift to pore sizes between $0.1 \mu \mathrm{m}$ and $0.01 \mu \mathrm{m}$ in the pastes exposed to freeze-thaw cycles (Figure 12). Pore refinement, which was more accentuated in the CS-PC pastes due to the pozzolanic reaction, had an adverse effect on CS-PC freeze-thaw resistance and was deemed to be the cause of paste specimen destruction, attributed to the microcracking induced by the freezing-mediated increase in the volume ${ }^{7}$ of the water in the capillary pores. 


\subsubsection{Colour test}

Colour measurements were taken on one of the surfaces of the $56 \mathrm{~d}$ specimens in contact with the various aggressive media. The lightness and colour coordinate values are shown in Figure 13. Although the lightness values were very similar in the two materials, the CS pastes were slightly lighter. Both the OPC and the CS-PC pastes in contact with seawater exhibited higher lightness values than the specimens soaked in water and the other aggressive media ( $80.83 \%$ in PC and $77.93 \%$ in CS-PC), a result of the formation of brucite on the specimen surface. As the XRD and SEM analyses showed, a thicker layer formed on OPC than on CS-PC, which would explain the lighter colour of the former.

The $\mathrm{a}^{*}$ and $\mathrm{b}^{*}$ values, in turn, were very close for both the OPC and CS-PC pastes, although in the samples exposed to seawater the points were significantly farther apart, again denoting the effect of brucite formation on the specimen surface, which is where the colour measurements were taken.

\section{Conclusions}

1.- These findings confirmed that CS additions have beneficial effects on cements, contributing to their chemical resistance to aggressive media such as seawater, $\mathrm{NaCl}$ and $\mathrm{Na}_{2} \mathrm{SO}_{4}$

2.- The inclusion of CS in cement does not alter the morphology of the resulting pastes, nor does its presence induce more expansive products in the pastes when exposed to aggressive media. 
3.- The more refined pore system in CS-PC than in OPC pastes due to the larger fraction of pores smaller than 0.01 microns in the former enhances paste durability against aggressive chemical agents but is detrimental to its freeze-thaw resistance.

4.- The inclusion of CS in cements induces no alteration in colour, with only a slight increase in lightness. The inference is that cements containing this addition would be apt for applications where aesthetics are a concern. Seawater, however, may cause chromatic decay due to the formation of brucite on the paste surface, with significant changes in lightness and colour coordinates in both OPC and CS-PC.

\section{Acknowledgements}

This research was funded by several Spanish Ministries (Projects BIA 2013-48876-C3-1-R, BIA 2013-48876-C3-2-R, BIA2016-76643-C3-1-R). Supply of the ceramic sludge used in this study by ADICEM Valorización S.L. is gratefully acknowledged.

\section{References}

1 European Standard EN 197-1 (2011), Standards. Cement. Part 1: Composition, specifications and conformity criteria for common cements.

${ }^{2}$ Mehta PK. Durability. Concrete: Structure, Properties and Materials. Edited by P.K. Mehta. Prentice-Hall, Englewood Cliffs, NJ, 1986.

${ }^{3}$ Frías M, Sánchez de Rojas MI. The influence of SIMn slag on chemical of blended cement pastes. Constr. Build. Mater. 2009; 23 (3): 1472-1475. 
${ }^{4}$ Lorenzo MP, Goñi S, Guerrero A. Activation of poszzzolanic reaction of hydrated Portland cement fly ash pastes in sulfate solution. J Am Ceram Soc. 2002; 85 (12): 3071-3075.

${ }^{5}$ Diamond S. Effect of microsilica (silica fume) on pore solution chemistry of cement pastes. J Am Ceram Soc. 1983; 66 (5): 82-84.

${ }^{6}$ Koch A., Steinegger U. A rapid Test for Cements for their begabiour under sulphate attack. Zem-Kalk-Gips. 1960; 7, 317-324.

${ }^{7}$ Liu L, Ye G, Schlangen E, Chen H, Qian Z, Sun W, Breugel K. Modeling of the internal damage of saturated cement paste due to ice crystallization pressure during freezing. Cem. Concr. Comp. 2011; 33 (5): 562-571.

${ }^{8}$ Andreola F, Barbieri L, Lancellotti I, Bignozzi MCh, Sandrolini F. New blended cement from polishing and glazing ceramic sludge. Inter. J App Ceram Techn, 2010; 7 (4): 546-555.

${ }^{9}$ Pelisser F, Steiner LR, Bernardin AM. Recycling of porcelain tile polishing residue in Portland cement. Hydration efficiency. Envir. Scien \& Techn. 2012; 46: 2368-2374.

${ }^{10}$ Sánchez de Rojas MI, Frías M, Sabador E, Asensio E, Rivera J, Medina C. Use of ceramic industry milling and glazing waste as an active addition in cement. J Am Ceram Soc. 2018; 101 (5): 2028-2037.

${ }^{11}$ European Standard EN 196-2 (2014), Method of testing cement. Part 2: Chemical analysis of cement.

${ }^{12}$ European Standard EN 450-1 (2013), Fly ash for concrete. Part 1: Definition, specifications and conformity criteria.

${ }^{13}$ Spanish Standard UNE 80117 (2012), Methods of testing cements. Physical analysis. Colour determination in clinkers and white cements. 
${ }^{14}$ ASTM-D114 (1999), Standard Practice for the preparation of substitute Ocean Water.

${ }^{15}$ Kakali G, Kasselouri V, Parissakis G. Hydration and strength development of cements produced from raw mixes containing MoO3, Nb2O5, WO3 and ZrO2. Cem Concr Res. 1989; $19(6): 968-72$.

${ }^{16}$ Gawlicki M, Czamarska D. Effect of $\mathrm{ZnO}$ on the hydration of Portland cement. $J$ Therm Anal Calorim. 1992; 38(9):2157-61.

${ }^{17}$ Stephan D, Mallmann R, Knöfel D, Härdt R. High intakes of Cr, Ni, and Zn in clinker. Part II. Influence on the hydration properties. Cem Concr Res. 1999; 29(12):1959-1967.

${ }^{18}$ Stephan D, Maleki H, Knofel D, Eber B, Hardtl R. Influence of Cr, Ni, and Zn on the properties of pure clinker phases - Part I. C3S. Cem Concr Res. 1999; 29 (4):545-52.

${ }^{19}$ Wang K, Nelsen DE, Nixon WA. Damaging effects of deicing chemicals on concrete materials. Cem. Concr. Compos., 2006; 28 (2): 173-188.

${ }^{20}$ Scherer GW. Stress from crystallization of salt. Cem Concr Res. 2004; 34 (9): 1613-1624.

${ }^{21}$ Sotiriadis K, Nikolopoulou E, Tsivilis S. Sulfate resistance of limestone cement concrete exposed to combined chloride and sulfate environment at low temperature. Cem Concr Compos., 2012; 34 (8): 903-910.

${ }^{22}$ Chen Y, Gao J; Tang L, Li X. Resistance of concrete against combined attack of chloride and sulfate under drying-wetting cycles. Constr. Build. Mater. 2016; 106: 650-658.

${ }^{23}$ Scherer GW. Stress from crystallization of salt. Cem Concr Res. 2004; 34 (9): 1613-1624.

${ }^{24}$ Li G, Zhang A, Song Z. Liu S, Zhang J. Ground granulated blast furnace slag effect on the durability of ternary cementitious system exposed to combined attack of chloride and sulfate. Constr. Build. Mater. 2018; 158: 640-648 
${ }^{25} \mathrm{Li} \mathrm{S}$, Roy DM. Investigation of relation between porosity, pore structure and chloride diffusion of fly ash and blended cement pastes. Cem. Concr. Res. 1986; 16 (5): 749-759.

${ }^{26}$. Florea MVA, Brouwers HJH. Modelling of chloride binding related to hydration products in slag-blended cements. Constr. Build. Mater. 2014; 64: 421-430.

${ }^{27}$ Soria F. Pozzolans and energy saving in building materials. Mater Constr. 1983; 190-191, $69-84$.

${ }^{28}$ Sánchez de Rojas MI, Frías M, Rodríguez O, Rivera J. Durability of blended cement pastes containing ceramic waste as a pozzolanic addition. J Am Ceram Soc. 2014; 97 (5): 1543-1551.

${ }^{29}$ Bensted J. Advances in cement technology: Chemistry, manufacture and testing. Hydration of Portland. Cement. $2^{\text {nd }}$ Edition. Ed: S.N. Ghosh. Edited: CRC Press. 2003. ISBN: 978-81-88305-04-9.

${ }^{30}$ Kalousek GL, Benton E.J. Mechanism of sea water attack on Cement Pastes. J ACI. $\quad 1970$; $67(9), 187-191$.

${ }^{31}$ Geng J, Easterbrook D, Li LY, Mo LW .The stability of bound chlorides in cement paste with sulfate attack. Cem Concr Res. 2015; 68: 211-222.

${ }^{32}$ Skalny J, Marchand J, Odler I. Sulfate attack on concrete, Spon Press, UK, 2002.

33 Richardson IG, Groves GW. Microstructure and microanalysis of hardened ordinary Portland cement pastes. J Mater Sci. 1993; 28 (1): 265-277.

${ }^{34}$ Hewlett, PC (ed.). Lea's Chemistry of Cement and Concrete. Elsevier, Amsterdam, 2003.

${ }^{35}$ Taylor HFW. Cement Chemistry. 2nd edition. Thomas Telford Publishing, London, 1997.

${ }^{36}$ Medina G, Sáez del Bosque IF, Frías M, Sánchez de Rojas MI, Medina C. J Clea Prod; 2017; 148: 467-476. 
${ }^{37}$ Fernández Canovas M. Hormigón. Edited by Colegio de Ingenieros de Caminos, Canales y Puertos, Servicio de Publicaciones, Colección Escuelas. Spain, 2004.

${ }^{38}$ Mehta PK, Manmohan D. Pore size distribution and permeability of hardened cement pastes, Proceedings of the $7^{\text {th }}$ Inter. Congress on the Chemistry of Cement, Edited by Septima, Paris, III, VII 1-5 (1980).

${ }^{39}$ Nyame BK, Illston JM. Capillary pore structure and permeability of hardened cement paste, Proceeding of the 7th Inter. Congress on the Chemistry of Cement, Edited by Septima, Paris, III, VI 181-185 (1980).

${ }^{40}$ Bassuoni MT, Rahman MM. Response of concrete to accelerated physical salt attack exposure. Cem. Concr. Res.; 2016, 79: 395-408. 


\section{FIGURE CAPTIONS:}

FIGURE 1. Variations in weight in OPC and CS-PC specimens exposed to water, seawater, $\mathrm{NaCl}$ or $\mathrm{Na}_{2} \mathrm{SO}_{4}$, by age

FIGURE 2. Flexural strength in OPC and CS-PC pastes in aggressive media by age

FIGURE 3. Compressive strength in OPC and CS-PC pastes in aggressive media by age

FIGURE 4. X-ray diffractograms for water-soaked OPC and CS-PC pastes

FIGURE 5. X-ray diffractograms for seawater-soaked OPC and CS-PC pastes

FIGURE 6. X-ray diffractograms for NaCl-soaked OPC and CS-PC pastes

FIGURE 7. X-ray diffractograms for $\mathrm{Na}_{2} \mathrm{SO}_{4}$-soaked OPC and CS-PC pastes

FUGURE 8. SEM micrographs of $56 \mathrm{~d}$, deionised water-soaked (a) OPC and (b) CS-PC pastes showing portlandite plates

FIGURE 9. SEM micrographs of $56 \mathrm{~d}$, seawater-soaked (a) OPC and (b) CS-PC pastes, showing brucite

FIGURE 10. SEM micrographs of $56 \mathrm{~d}, \mathrm{NaCl}$-soaked (a) OPC and (b) CS-PC pastes, showing hydration products containing $\mathrm{Al}, \mathrm{Cl}$ and $\mathrm{Ca}$ (Friedel's salt)

FIGURE 11. Pore size distribution curves for $56 \mathrm{~d}$ OPC and CS-PC in water and aggressive media

FIGURE 12. Pore size distribution curves for specimens exposed to freeze-thaw cycles

FIGURE 13. Lightness and colour coordinates for $56 \mathrm{~d}$, deionised water-, seawater-, NaCl- and 
$\mathrm{Na}_{2} \mathrm{SO}_{4}$-soaked OPC and CS-PC pastes 
FIGURE 1. Variations in weight in OPC and CS-PC specimens exposed to water, seawater, $\mathrm{NaCl}$ or $\mathrm{Na2SO4,}$ by age

$84 \times 53 \mathrm{~mm}(300 \times 300$ DPI $)$ 


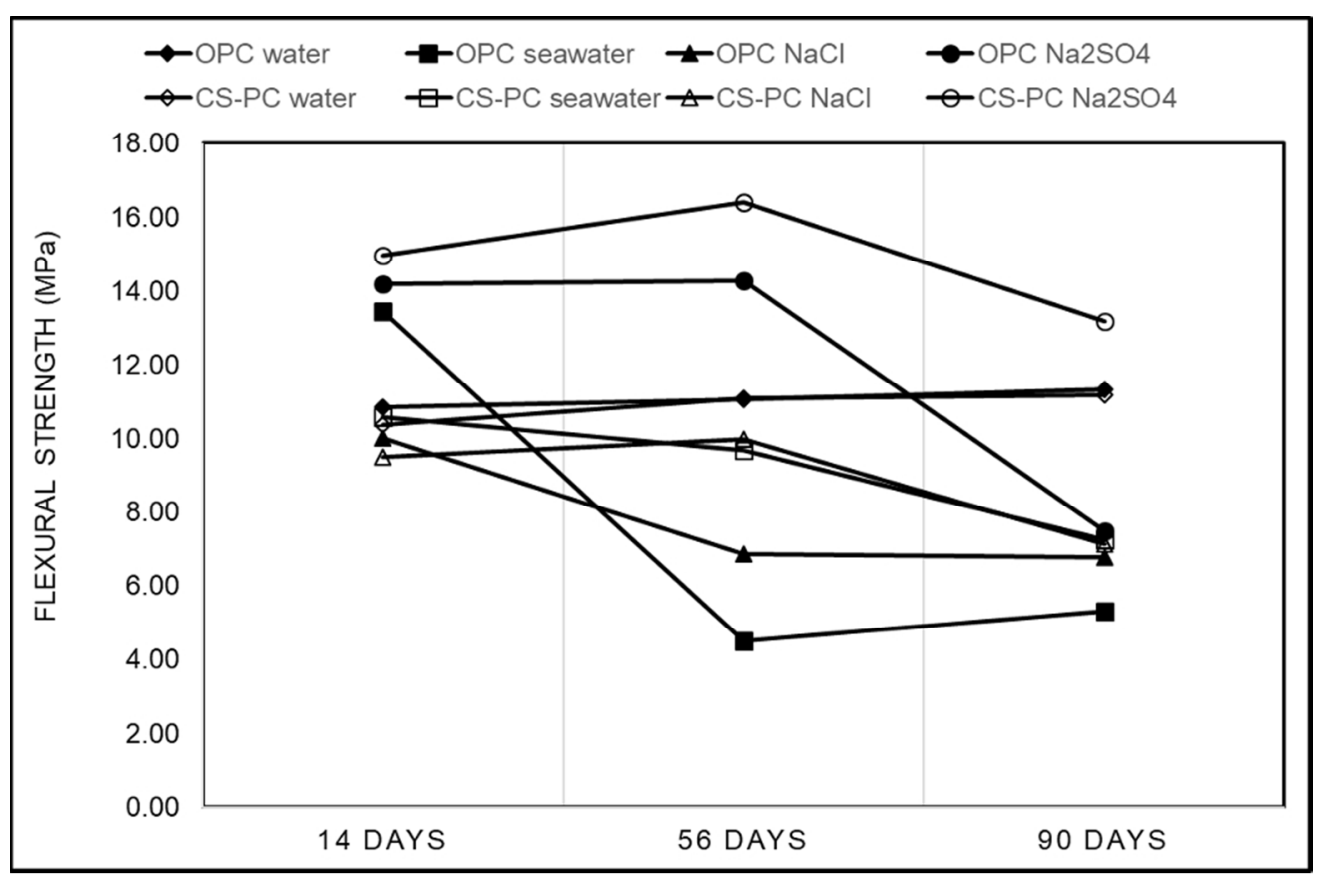

FIGURE 2. Flexural strength in OPC and CS-PC pastes in aggressive media by age $84 \times 55 \mathrm{~mm}(300 \times 300$ DPI $)$ 


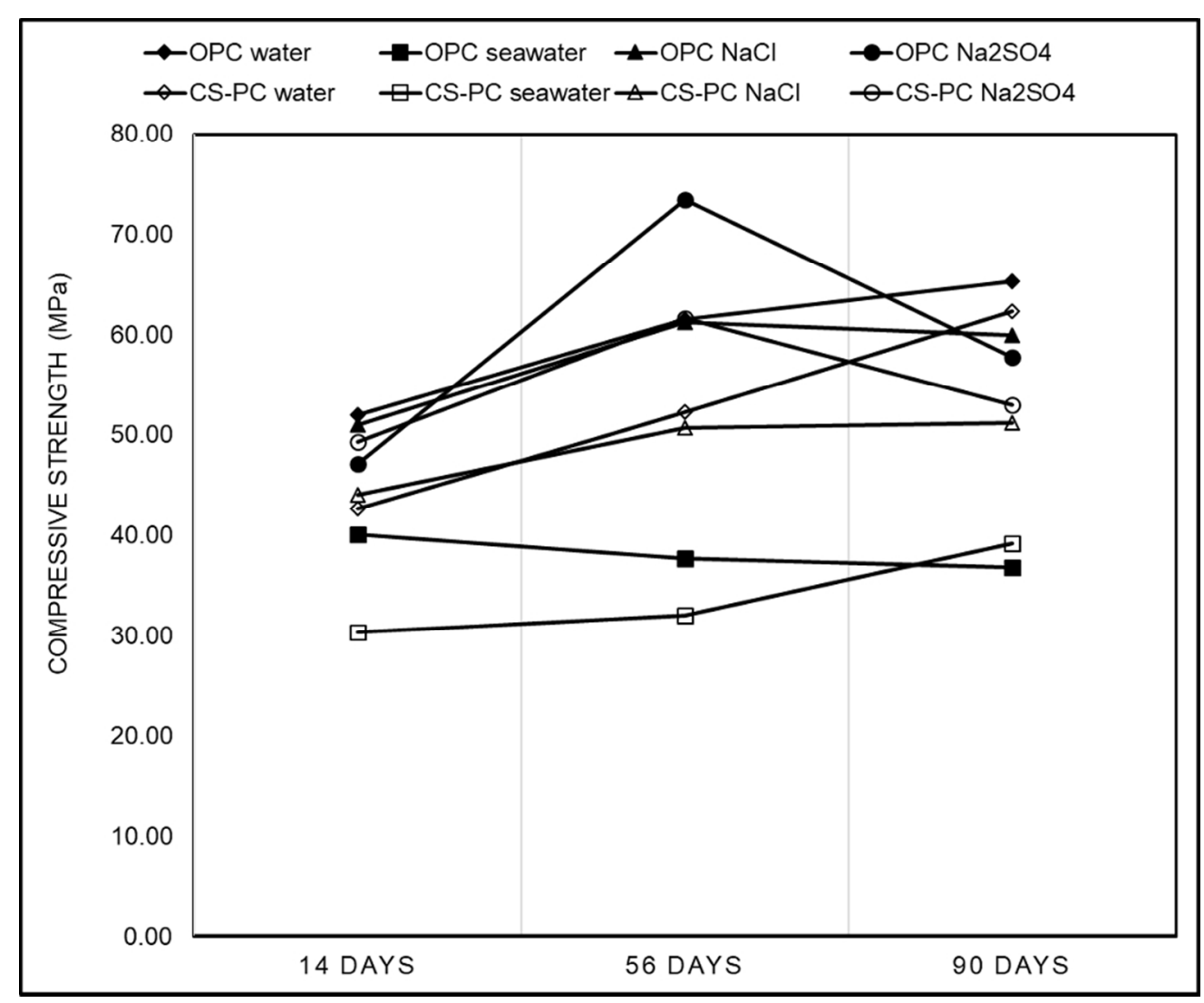

FIGURE 3. Compressive strength in OPC and CS-PC pastes in aggressive media by age $84 \times 70 \mathrm{~mm}(300 \times 300$ DPI $)$ 

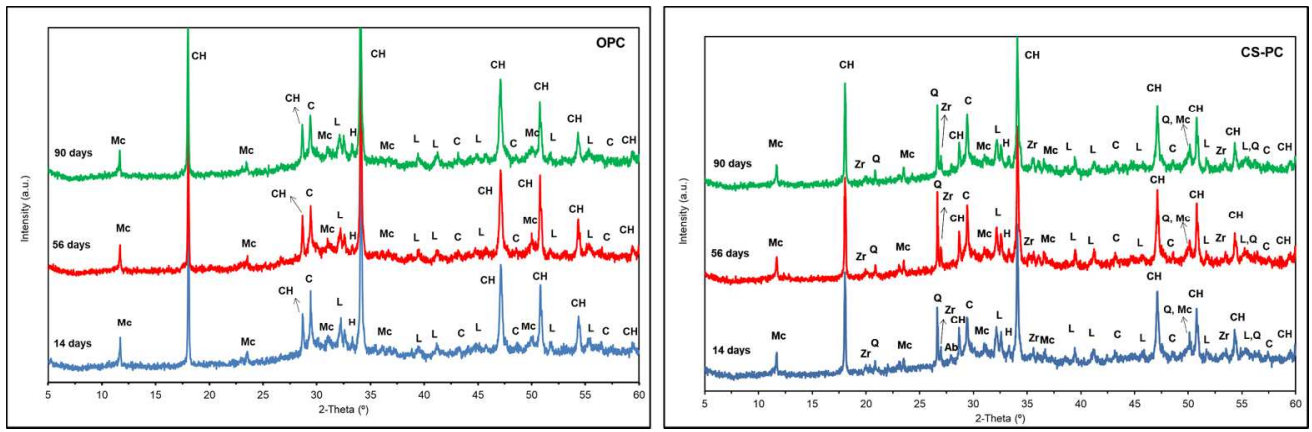

FIGURE 4. X-ray diffractograms for water-soaked OPC and CS-PC pastes $169 \times 54 \mathrm{~mm}(300 \times 300$ DPI $)$ 


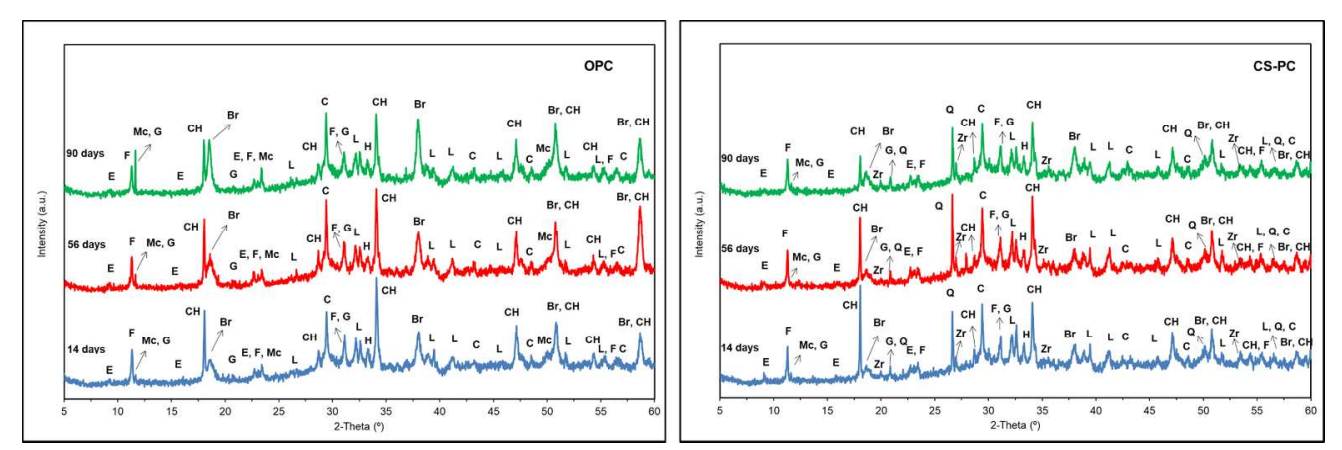

FIGURE 5. X-ray diffractograms for seawater-soaked OPC and CS-PC pastes $169 \times 54 \mathrm{~mm}(300 \times 300$ DPI) 

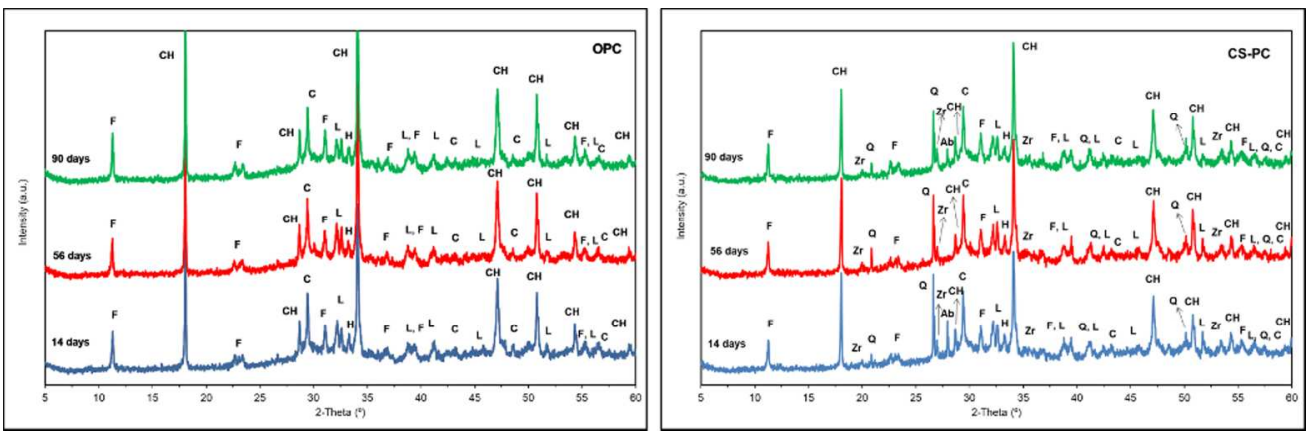

FIGURE 6. X-ray diffractograms for $\mathrm{NaCl}$-soaked OPC and CS-PC pastes $169 \times 54 \mathrm{~mm}(300 \times 300$ DPI $)$ 


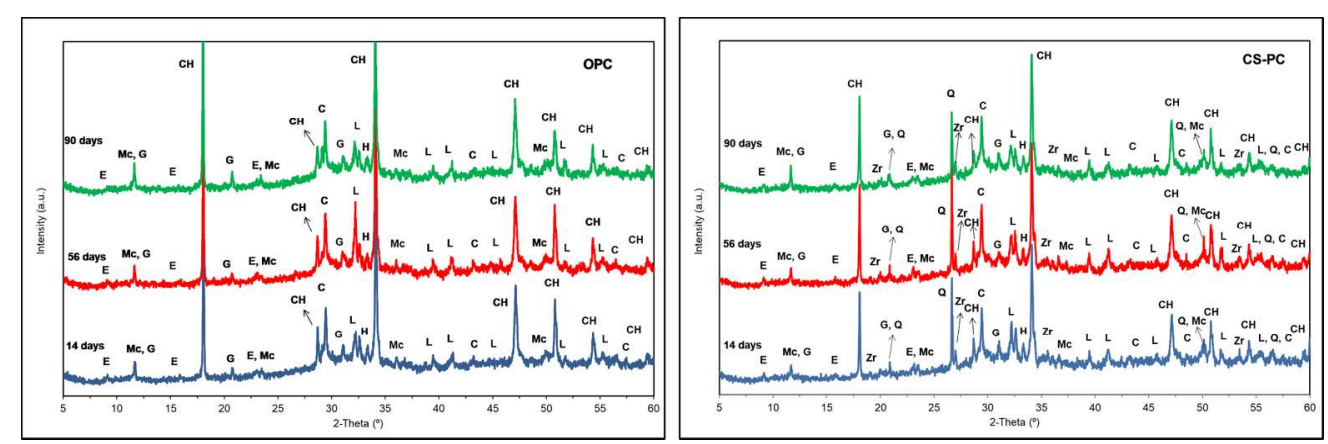

FIGURE 7. X-ray diffractograms for Na2SO4-soaked OPC and CS-PC pastes $169 \times 54 \mathrm{~mm}(300 \times 300$ DPI $)$ 

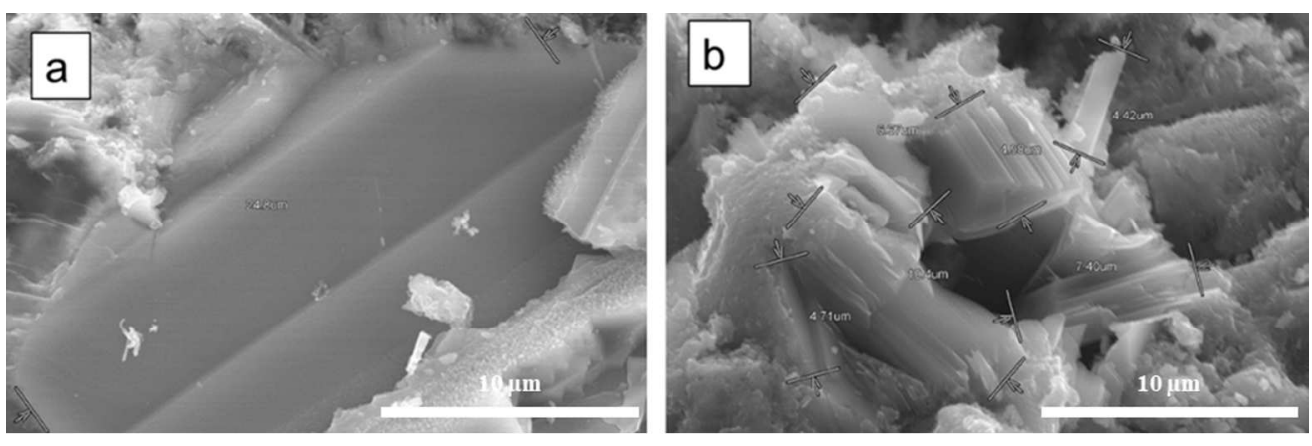

FIGURE 8. SEM micrographs of $56 \mathrm{~d}$, deionised water-soaked (a) OPC and (b) CS-PC pastes showing portlandite plates

$169 \times 54 \mathrm{~mm}(300 \times 300 \mathrm{DPI})$ 

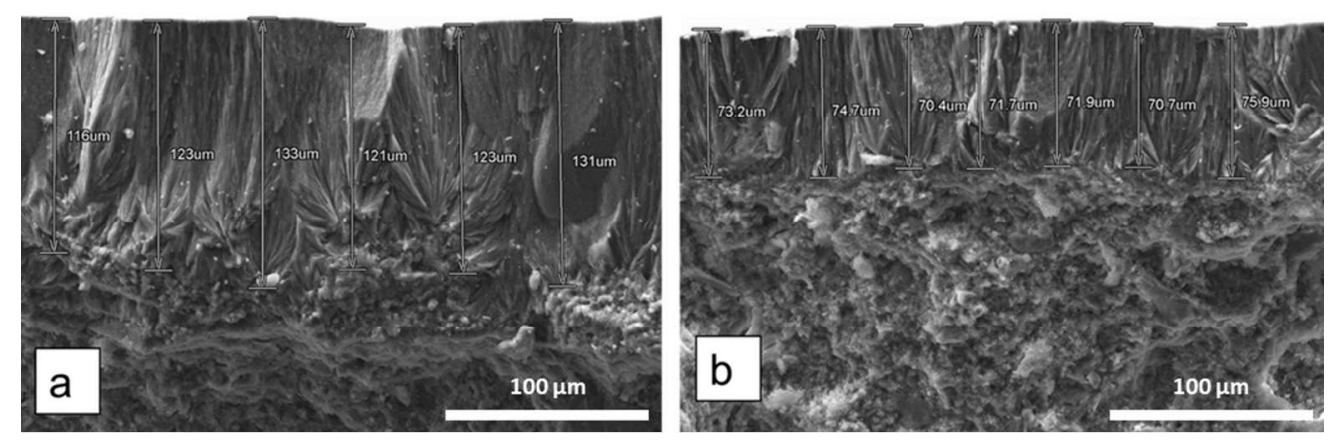

FIGURE 9. SEM micrographs of $56 \mathrm{~d}$, seawater-soaked (a) OPC and (b) CS-PC pastes, showing brucite $169 \times 54 \mathrm{~mm}(300 \times 300$ DPI $)$ 


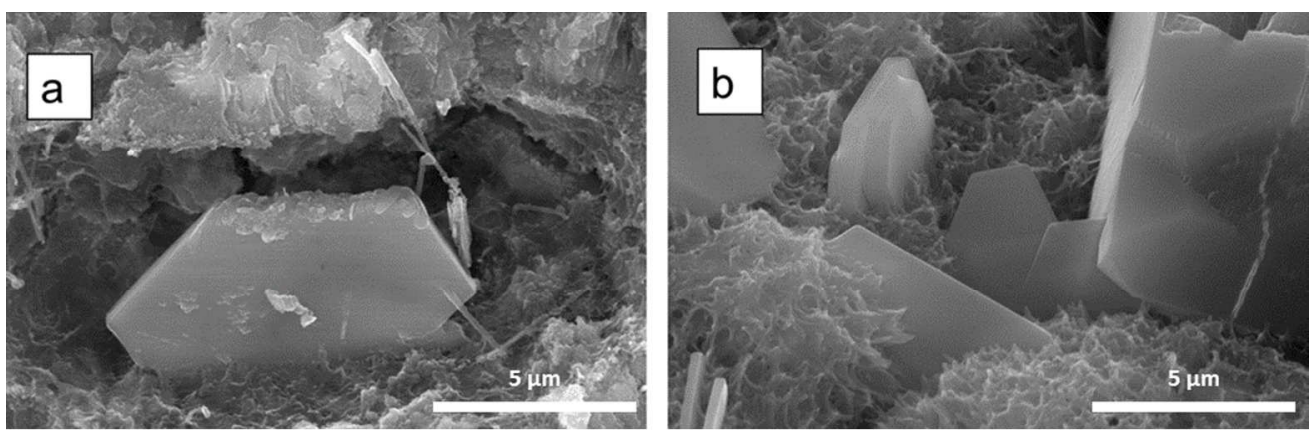

FIGURE 10. SEM micrographs of $56 \mathrm{~d}, \mathrm{NaCl}$-soaked (a) OPC and (b) CS-PC pastes, showing hydration products containing $\mathrm{Al}, \mathrm{Cl}$ and $\mathrm{Ca}$ (Friedel's salt)

$169 \times 54 \mathrm{~mm}(300 \times 300 \mathrm{DPI})$ 

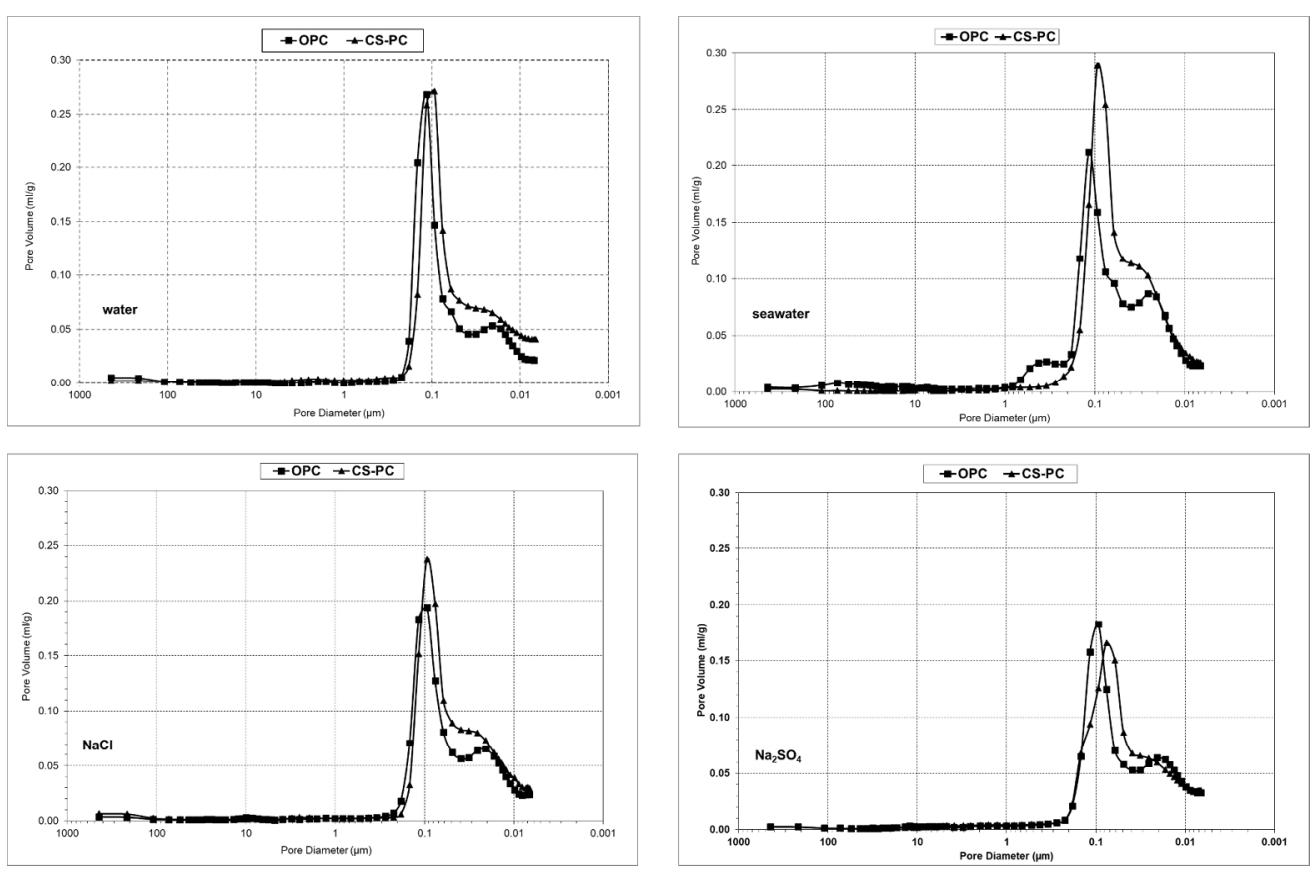

FIGURE 11. Pore size distribution curves for $56 \mathrm{~d}$ OPC and CS-PC in water and aggressive media $169 \times 110 \mathrm{~mm}(300 \times 300 \mathrm{DPI})$ 


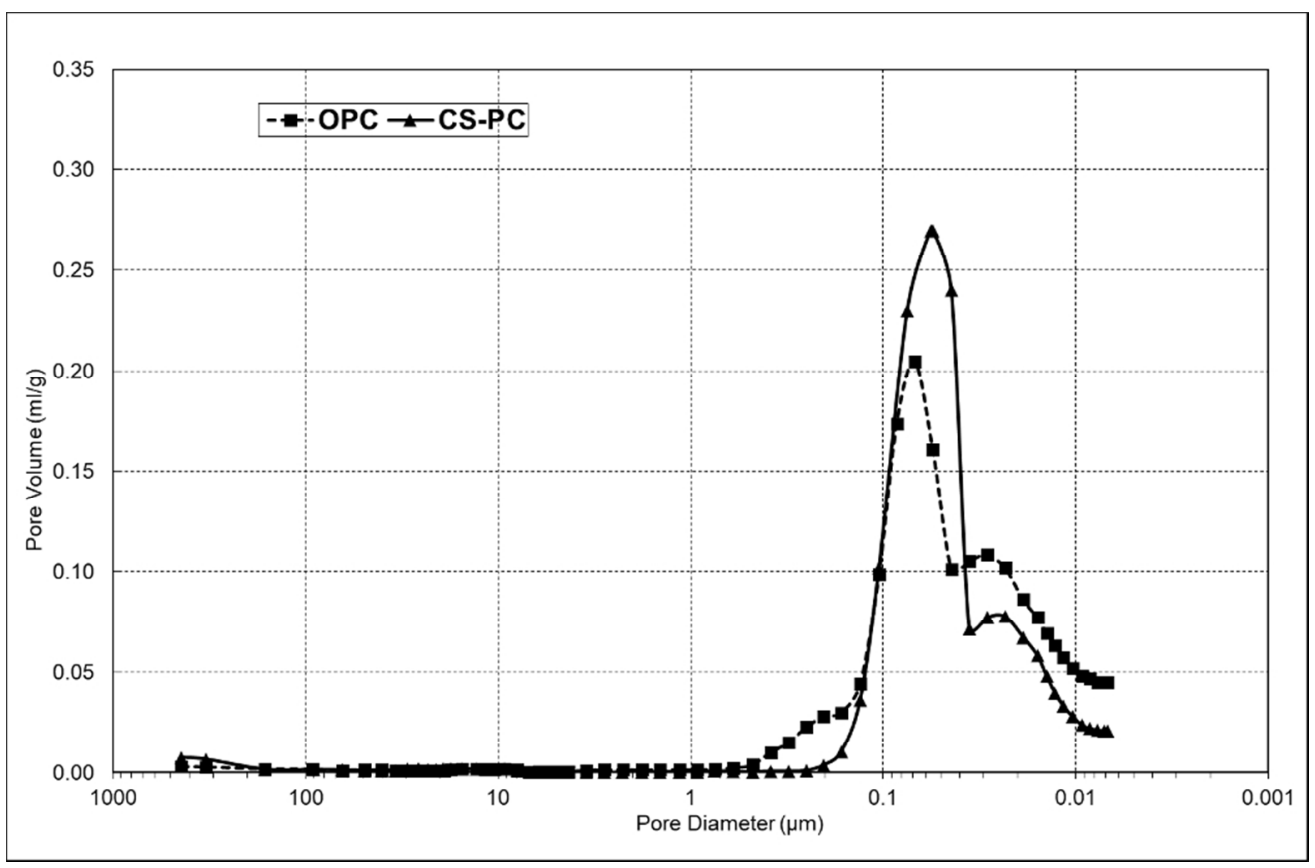

FIGURE 12. Pore size distribution curves for specimens exposed to freeze-thaw cycles $84 \times 55 \mathrm{~mm}(300 \times 300$ DPI $)$ 

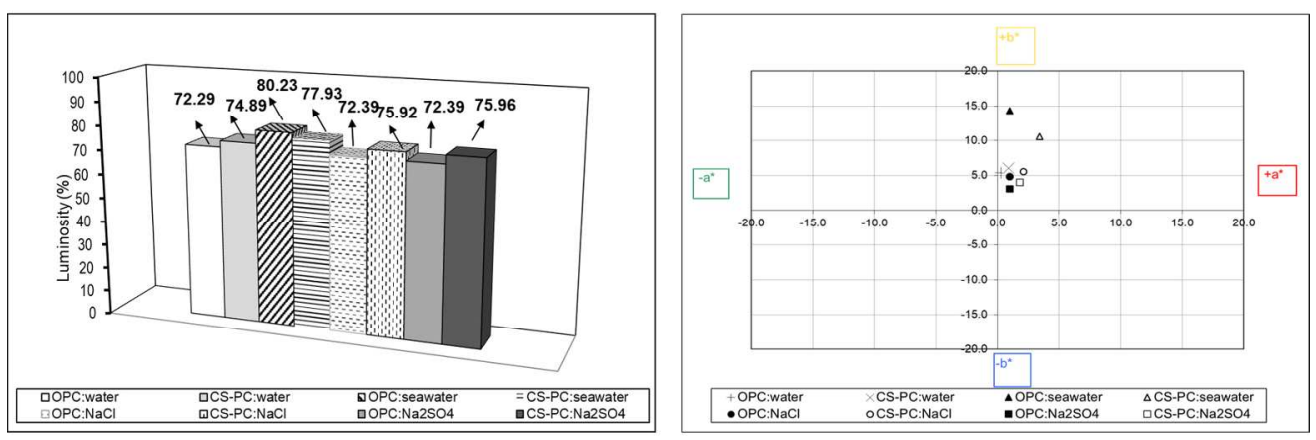

FIGURE 13. Lightness and colour coordinates for $56 \mathrm{~d}$, deionised water-, seawater-, $\mathrm{NaCl}-$ and Na2SO4soaked OPC and CS-PC pastes

$169 \times 55 \mathrm{~mm}(300 \times 300 \mathrm{DPI})$ 
Table 1. Majority constituents in starting materials (wt\%)

\begin{tabular}{|c|c|c|c|c|c|c|c|c|c|c|}
\hline \multirow[t]{2}{*}{ Material } & \multicolumn{10}{|c|}{ Chemical constituent (\%) } \\
\hline & $\mathrm{SiO}_{2}$ & $\mathrm{Al}_{2} \mathrm{O}_{3}$ & $\mathrm{Fe}_{2} \mathrm{O}_{3}$ & $\mathrm{CaO}$ & $\mathrm{MgO}$ & $\mathrm{Na}_{2} \mathrm{O}$ & $\mathrm{K}_{2} \mathrm{O}$ & $\mathrm{SO}_{3}$ & $\mathrm{Cl}^{-}$ & $\mathrm{LoI}_{(\mathrm{a})}$ \\
\hline $\mathrm{OPC}$ & 18.83 & 4.36 & 2.55 & 63.21 & 1.85 & 0.16 & 0.82 & 3.13 & 0.05 & 3.11 \\
\hline $\mathrm{CS}$ & 58.90 & 16.10 & 2.79 & 3.50 & 1.00 & 1.80 & 2.40 & 0.10 & 0.01 & 3.63 \\
\hline
\end{tabular}


Table 2. Minority constituents in starting materials (wt\%)

\begin{tabular}{|c|c|c|c|c|c|c|c|c|}
\hline \multirow[t]{2}{*}{ Material } & \multicolumn{8}{|c|}{ Chemical constituent $(\%)$} \\
\hline & $\mathrm{PbO}$ & $\mathrm{BaO}$ & $\mathrm{TiO}_{2}$ & $\mathrm{CrO}$ & $\mathrm{ZnO}$ & $\mathrm{ZrO}_{2}$ & $\mathrm{CaO}_{\text {Free }}$ & $\mathrm{P}_{2} \mathrm{O}_{5(\mathrm{~b})}$ \\
\hline $\mathrm{OPC}$ & - & - & 0.22 & 0.01 & 0.04 & - & - & - \\
\hline $\mathrm{CS}$ & 1.70 & 0.97 & 0.21 & 0.30 & 5.10 & 1.28 & - & 0.35 \\
\hline
\end{tabular}


Table 3. Corrosion indices $\left(\mathrm{F}_{\mathrm{sx}} / \mathrm{F}_{\mathrm{sw}}\right)$ for $\mathrm{OPC}$ and CS-PC pastes versus time

\begin{tabular}{ccccc}
\hline Pastes & Water & Seawater & $\mathrm{NaCl}$ & $\mathrm{Na}_{2} \mathrm{SO}_{4}$ \\
\hline OPC & 1 & 0.41 & 0.62 & 1.29 \\
CS-PC & 1 & 0.87 & 0.90 & 1.48 \\
\hline
\end{tabular}

$\mathrm{F}_{\mathrm{sx}}=$ flexural strength after soaking in aggressive solutions

$\mathrm{F}_{\mathrm{sw}}=$ flexural strength after soaking in water 
Table 4. $\mathrm{F}_{\mathrm{sx}} / \mathrm{C}_{\mathrm{sx}}$ ratios for OPC and CS-PC pastes after soaking in aggressive solutions versus time (days)

\begin{tabular}{|c|c|c|c|c|c|c|c|c|c|c|c|c|}
\hline \multirow[t]{2}{*}{ Pastes } & \multicolumn{3}{|c|}{ Water } & \multicolumn{3}{|c|}{ Seawater } & \multicolumn{3}{|c|}{$\mathrm{NaCl}$} & \multicolumn{3}{|c|}{$\mathrm{Na}_{2} \mathrm{SO}_{4}$} \\
\hline & $14 d$ & $56 \mathrm{~d}$ & $90 \mathrm{~d}$ & $14 d$ & $56 \mathrm{~d}$ & $90 \mathrm{~d}$ & $14 d$ & $56 \mathrm{~d}$ & $90 d$ & $14 d$ & $56 \mathrm{~d}$ & $90 \mathrm{~d}$ \\
\hline$\overline{\mathrm{OPC}}$ & 0.21 & 0.18 & 0.17 & 0.34 & 0.12 & 0.14 & 0.19 & 0.11 & 0.11 & 0.30 & 0.19 & 0.13 \\
\hline CS-PC & 0.25 & 0.22 & 0.20 & 0.35 & 0.30 & 0.18 & 0.22 & 0.20 & 0.14 & 0.30 & 0.27 & 0.25 \\
\hline
\end{tabular}


TABLE 5. Mineralogical data for OPC and CS-PC

\begin{tabular}{|c|c|c|c|c|c|c|}
\hline \multirow{2}{*}{$\begin{array}{c}\text { Compound } \\
\text { Monocarboaluminate } \\
\text { hydrate }\end{array}$} & \multirow{2}{*}{$\frac{\text { Symbol }}{\mathrm{Mc}}$} & \multirow{2}{*}{$\begin{array}{c}\text { Chemical formula } \\
3 \mathrm{CaOAl}_{2} \mathrm{O}_{3} \mathrm{CaCO}_{3} 11 \mathrm{H}_{2} \mathrm{O}\end{array}$} & \multicolumn{3}{|c|}{ Diffraction lines $\left(2 \theta /{ }^{\circ}\right)$} & \multirow{2}{*}{$\begin{array}{r}\text { COD ID } \\
2007668\end{array}$} \\
\hline & & & 11.71 & 23.54 & 37.18 & \\
\hline Ettringite & $\mathrm{E}$ & $(\mathrm{CaO})_{6}\left(\mathrm{Al}_{2} \mathrm{O}_{3}\right)\left(\mathrm{SO}_{3}\right)_{3} 32 \mathrm{H}_{2} \mathrm{O}$ & 9.14 & 15.86 & 23.03 & 9012922 \\
\hline Portlandite & $\mathrm{CH}$ & $\mathrm{Ca}(\mathrm{OH})_{2}$ & 34.10 & 50.84 & 18.05 & 1001768 \\
\hline Quartz & Q & $\mathrm{SiO}_{2}$ & 26.65 & 20.85 & 50.11 & 9012600 \\
\hline Hematite & $\mathrm{H}$ & $\mathrm{Fe}_{2} \mathrm{O}_{3}$ & 33.14 & 35.63 & 39.24 & 5910082 \\
\hline Calcite & $\mathrm{C}$ & $\mathrm{CaCO}_{3}$ & 29.40 & 48.51 & 47.49 & 1010928 \\
\hline Larnite & $\mathrm{L}$ & $\mathrm{Ca}_{2} \mathrm{O}_{4} \mathrm{Si}$ & 31.94 & 32.59 & 32.17 & 9012793 \\
\hline Zircon & $\mathrm{Zr}$ & $\mathrm{ZrSiO}_{4}$ & 26.94 & 53.40 & 35.59 & 5000119 \\
\hline Gypsum & G & $\mathrm{Ca}_{2} \mathrm{SO}_{4} 2 \mathrm{H}_{2} \mathrm{O}$ & 20.78 & 29.20 & 31.14 & 1010981 \\
\hline Friedel's salt & $\mathrm{F}$ & $3 \mathrm{CaOAl}_{2} \mathrm{O}_{3} \mathrm{CaCl}_{2} 10 \mathrm{H}_{2} \mathrm{O}$ & 11.20 & 30.96 & 23.06 & 6000181 \\
\hline Brucite & $\mathrm{Br}$ & $\mathrm{Mg}(\mathrm{OH})_{2}$ & 38.05 & 58.74 & 50.72 & 1000054 \\
\hline
\end{tabular}

